\title{
From lab bench to product catalog
}

\author{
Commercialization of academic research is increasing and provides important benefits, but it \\ remains difficult, and recent developments bring new challenges.
}

Before the 1980 Bayh-Dole Act allowed universities to own inventions based on US federally funded research, commercialization of these innovations was almost nonexistant. Policies designed to protect the public by mandating that inventions resulting from federally funded research be made freely available had failed. In the 30 years since the Bayh-Dole Act was enacted, federally funded research has resulted in $>6,000$ new US companies and $>4,350$ university-licensed products.

But the increased commercialization of academic research is not without its critics, who correctly highlight the increased pressure on researchers to pursue work with greater short-term and commercial potential. Too much focus on short-term applied research would cripple real innovation. Still, if a substantial portion of academic innovations can aid basic research, this pressure for applications will boost basic research output.

Researchers only benefit from inventions if they are usable, and this may require commercialization. Many inventions are too expensive for researchers in a single laboratory to replicate, and it takes a lot of work to move a protocol that works in an expert's hands to one that works in anyone's hands. A company, unlike academic researchers, is better equipped for this kind of optimization.

Authors often seem to worry that commercialization plans will stigmatize the perceived objectivity of their research. But reviewers and readers appear to be increasingly concerned with accessibility and view commercialization as beneficial. Nature Methods does not consider the status of commercialization in making publication decisions. We do try to ensure that authors provide sufficient methodological details for others to reproduce the invention or procedure without relying on commercialization, but an optimized product will often do more good than detailed instructions.

Once an academic decides to try to commercialize an invention, where can they turn? Most have little interest or experience to seek out potential licensees or obtain start-up funding. This need is starting to be addressed. The Association of University Technology Managers announced that late this year they will launch a web portal to help facilitate licensing and investments for university startups. This should ease the burden on technology transfer offices and help level the playing field between institutions. SciBX: Science-Business eXchange, a joint venture of BioCentury and Nature Publishing Group, also provides a service to increase communication between researchers and businesspeople.
But there is no substitute for direct personal contact. Informal networking can be critical to success and is often easier at institutions with a strong history of commercial activity. For researchers without these connections, Nature Medicine and Nature Biotechnology have been hosting SciCafé networking events since 2007 to establish links between academic researchers and members of the business community interested in funding or licensing new inventions (Anonymous. Nat. Med. 15, 1095; 2009).

Now US academics face another change in the law. The America Invents Act will presumably be signed into law by the time this is published. This legislation, when it goes into full effect one year later, will partially harmonize US patent law with that in the rest of the world by shifting from a 'first to invent' to a 'first to file' system. Researchers may want to adjust their behavior accordingly. Under the unique US first-to-invent system, technology transfer offices record most inventions as confidential 'invention disclosures' that protect their intellectual property indefinitely until the invention is patented. Without this protection, researchers will need to be even more secretive until an invention is patented or published, or risk losing their intellectual property.

A published paper or other public disclosure of an invention will still make it impossible to patent it in another country, but a curious feature of the new law blocks anyone else from filing a patent on this invention in the United States, whereas the author has one year to do so. But the inability to secure patents in global markets-resulting from the public disclosure-probably makes this option unattractive for commercialization.

Ultimately, the global marketplace and researchers' desire to publish their inventions will limit the impact of the patent law changes on behavior. Inventors will not have the protection of the invention disclosure to try and solicit business partners before applying for a US patent-and opening the 30 -month window to pay the large sums necessary to obtain patents in other countries-but academic demands to publish already force many researchers to submit a patent application before they might otherwise want to.

Although large companies may continue to patent every potential invention, researchers will need to be more circumspect and select suitably mature inventions with sufficient commercial potential to attract financing. Although the ultimate impact will not be known for years, it is possible that this 'focusing of effort' on the most promising inventions, and other benefits of the law, will outweigh the negative aspects. 